\section{$\angle$ Research Square}

Preprints are preliminary reports that have not undergone peer review.

They should not be considered conclusive, used to inform clinical practice, or referenced by the media as validated information.

\title{
SARS-Cov-2 Clearance in Term of Cycle Threshold (Ct) During First Two Waves of COVID-19 in Pakistan: A Phenomenon of Delayed Viral Clearance Post- Corticosteroid Treatment.
}

\author{
Umar Saeed ( $\sim$ umarsaeed15@yahoo.com ) \\ Islamabad Diagnostic Center Pakistan \\ Sara Rizwan Uppal \\ Islamabad Diagnostic Center Pakistan \\ Zahra Zahid Piracha \\ Islamabad Diagnostic Center Pakistan \\ Rizwan Uppal \\ Islamabad Diagnostic Center Pakistan
}

\section{Short report}

Keywords: SARS-CoV-2, COVID-19, Ct value delay, Pakistan, Corticosteroid.

Posted Date: May 24th, 2021

DOI: https://doi.org/10.21203/rs.3.rs-535561/v1

License: (c) (i) This work is licensed under a Creative Commons Attribution 4.0 International License. Read Full License 


\section{Abstract}

SARS-CoV-2 is recently emerged virus, which caused millions of deaths, all over the world. To tackle COVID-19 pandemic, there is an utmost need for in-depth analysis of viral replication. We aimed to examine viral load in SARS-CoV-2 patients during first two waves of COVID-19 in Pakistan. 225,615 suspected subjects from 75 different regions of Pakistan were selected in the study. SARS-CoV-2 RNAs were detected via real time PCR. During first wave (period of June-July, 2020) of COVID-19 the prevalence of SARS-CoV-2 was 20.38\%. However during second wave (period of NovemberDecember, 2020) of COVID-19, the rate of prevalence was $9.41 \%$. During first wave of COVID-19 96.31\% of participants remained PCR positive for 14 to 21 days, $3.39 \%$ of subjects showed positive results for 22 to 35 days, while delayed Ct values were observed among $0.26 \%$ of participants for 36 to 49 days. However, during second wave of COVID-19 89.31\% of the subjects exhibited symptoms and showed real-time PCR positive results for 14 to 21 days, $9.42 \%$ showed positive results for 22 to 35 days, while significantly delayed Ct value results were observed among $1.026 \%$ of participants for 36 to 63 days ( 3.95 times higher than first wave). In contrast to first wave of COVID-19, the factors that were different in second wave were neither viral (different strains) nor host (same population). But treatment factors changed significantly. As during second wave besides azithromycin, corticosteroid dexamethasone consumption was increased consequently causing delayed Ct value negativity. This suggests that corticosteroid treatment might be linked with delayed $\mathrm{Ct}$ value or viral clearance. This study is crucial for re-considering effective therapeutic options against COVID-19.

\section{Introduction}

The ongoing pandemic of severe acute respiratory syndrome coronavirus 2 (SARS-CoV-2) has caused more than 153 million cases of Coronavirus disease-19 (COVID-19), resulting into 3.2 million deaths worldwide, worst affected areas include United States and India (1). The virus preferentially infects respiratory tract cells, but may also cause severe damage to other organs such as conjunctiva, pharynx, brain, lungs, liver, kidneys, heart and several others (2-5). The virus constitutes of envelop (E), matrix core protein $(M)$, nucleocapsid $(N)$, and surface spike glycoprotein (S). The virus penetrates the host Alveolar type 2 progenitor (AT2) cells expressing angiotensin-converting enzyme 2 (ACE2) through which spike surface glycoprotein interact with receptor binding domain. The virus hijacks cellular metabolic pathways such as G-protein-coupled receptors (GPCRs) linked pathways, c-Jun N-terminal Kinase (JNK), Janus Tyrosine Kinase (JAK)-Signal Transducer and Activator of Transcription (STAT) signaling pathways to favor enhanced viral transmission (6).

In Pakistan, the first case of COVID-19 was reported from Karachi on February 26, 2020, while afterwards, SARS-CoV-2 rapidly sprout nationwide causing infection in millions. During first wave of SARS-CoV-2 it has been intimated by the prediction analysis of Medical Research Council Centre for Global Infectious Disease, Imperial College London that the expected number of deaths due to COVID-19 might exceed 80,000 per day, however through admirable management skills of National Command Operation Center (NCOC) of Pakistan and implementation of standard operating procedures via efficient smart lock down policies, the first wave of COVID-19 was controlled. These efforts were recognized worldwide and appreciated by WHO and several other countries. And there were $<10$ deaths per day at that time and 1 st wave recorded down with aforementioned efforts (7).

The second wave of COVID-19 emerged due to poor compliance, political gathering, festivals etc. which resulted in rise of numbers of COVID-19 patients. In second wave based upon new global guidelines, the inflammatory damage caused by SARS-CoV-2 significantly caused critical COVID-19. In such patients, steroids and azithromycin showed promising results in term of morbidity and mortality. Of note in-appropriate usage of azithromycin for SARS-CoV-2-related disease could also worsen Extensively Drug Resistant (XDR) typhoid in Pakistan, and may not be prescribed during early phase of SARS-CoV-2 infection (8). Since, it has been reported that usage of corticosteroids in patients with early SARS and MERS infection were linked with delayed viral clearance with no clear benefits in term of length of hospitalization, survival or mechanical ventilation. And usage of corticosteroids for management during initial phase of SARS-CoV-2 infection is not recommended (9). However among critically ill SARSCoV-2 infected ones, corticosteroids treatment showed clear survival benefit (10). Accordingly, World Health Organization recommends systemic corticosteroids treatment for critically SARS-CoV-2 infected patients (11). There is a dearth of research on SARS-CoV-2 viral clearance after steroid treatment. The aim of this study was to estimate SARS-CoV-2 viral load (cycle thresh hold (Ct) values) and consequent viral clearance during initial two waves of COVID-19 in Pakistan.

\section{Material And Methods}

To compare the viral clearance in term of cycle threshold (Ct) values of real-time PCR during first two wave of COVID-19 epidemics in Pakistan, 225,615 COVID-19 suspected subjects were selected across 75 different regions of Pakistan including federally-administered Islamabad Capital Territory, Punjab, Khyber Pakhtunkhwa, Sindh, Balochistan and Azad Kashmir. About 225,615 suspected SARS-CoV-2 infected patients were included in the study during first two COVID-19 epidemics across the nation between June-July 2020, and November-December 2020.

After pre-test counseling via trained professional counselors, history of SARS-CoV-2 suspected patients and comprehensive medical examination was conducted. Ethical approval was obtained from all study participants. The institutional review board of Islamabad Diagnostic Center approved the study. After obtaining patients formal consent, the specimens were sent for molecular analysis at IDC specialized center for COVID-19, G-8 Markez Islamabad, Pakistan. The study investigators had professional background, full understanding and knowledge of specific contents of the protocol and all indicators through training related to SARS-CoV-2 diagnostics. The accuracy and integrity of COVID-19 testing was verified using 
gold standard means. The National Institute of Health $(\mathrm{NIH})$, Islamabad, Pakistan Quality Control Laboratory approved IDC laboratory to ensure the standardization of experimental operating procedures.

After RNA extraction through Auto pure 32 Zybio China, from suspected COVID-19 samples, using standard Primerdesign, SARS-CoV-2 RNA positivity was detected via real-time polymerase chain reaction (Roche, USA). The assay included positive control template and RNA internal extraction control (Saeed U et al., 2021). World health organization recommended USFDA approved triple target genes design (including SARS-CoV-2 RNA-dependent RNA polymerase gene, Sarbecovirus E gene, SARS-CoV-2 N gene) was used along with Seegene kit (\#RP10244Y Allplex ${ }^{\text {TM }}$ 2019-nCoV Assay, Seegene South Korea) with detection limit of (100) copies/ml. The positive samples having exponential growth curve and Ct value $\leq 40$ were considered COVID-19 positive. Discordant results were repeated or excluded. From each sample's nucleic acid, $5 \mu$ l of RNA template was used along with $15 \mu$ l of the One-step real-time PCR Master-mix. The conditions for thermocycling were; $30 \mathrm{~min}$ at $48^{\circ} \mathrm{C}$ for reverse transcription, 10 min at $95^{\circ} \mathrm{C}$ and $45 \mathrm{cycles}$ of $15 \mathrm{~s}$ at $95^{\circ} \mathrm{C}$ and $1 \mathrm{~min}$ at $60^{\circ} \mathrm{C}$ (Saeed $\mathrm{U}$ et al., 2021). The Seegene kit was stored at $-20^{\circ} \mathrm{C}$ freezer, however extracted RNA was stored at $-70^{\circ} \mathrm{C}$ deep freezer. All of the test procedures were applied in accordance with standardized manufacturing protocols.

\section{Results}

To examine the impact changes of second COVID-19 wave (Nov-Dec, 2020) on delayed negative cycle threshold (Ct) values and associated course of illness or outcomes, in comparison to first wave of SARS-CoV-2 infections (June-July, 2020) in general population of Pakistan, we selected 225,615 SARS-CoV-2 suspected patients across the country. A total of 48,723 and 176,892 suspected SARS-CoV-2 infected patients were selected during the period of 1 st June to 31 st July 2020, and 1st November to 31st December 2020, respectively. Among these patients, SARS-CoV-2 RNA positive cases via real time PCR were selected for examining correlation between Ct values and disease progression.

The prevalence of SARS-CoV-2 during period of June-July, 2020 and November-December, 2020 among general population of Pakistan was $20.38 \%$ and $9.41 \%$, respectively. Among selected subjects during first and second COVID-19 waves 66.92\% (June-July, 2020) and 65.7\% (Nov-Dec, 2020) were males, 33.07\% (June-July, 2020) and 34.32\% (Nov-Dec, 2020) were females, and 4\% (June-July, 2020) and 12.7\% (Nov-Dec, 2020) were children. During second wave of COVID-19 attack, the rate of infection among children was increased to approximately three times than first wave.

During first peak wave of COVID-19 attack among Pakistani population (during June-July) COVID-19 infection detected via real-time PCR with considerably Ct values persisted for approximately 2 to 3 weeks (14 to 21 days) among $96.31 \%$ of participants. And afterwards became real-time PCR negative. While 3.39\% of participants showed COVID-19 symptoms and real-time PCR positive results for 3 to 5 weeks (approximately 22 to 35 days). Delayed Ct positive values were observed only among $0.26 \%$ of the participants for 5 to 7 weeks (approximately 36 to 49 days) as shown in Fig. 1.

However, during November-December, 2020 among real-time PCR confirmed positive patients, Ct value or viral loads and disease severity persisted for 2 to 3 weeks (approximately 14 to 21 days) among $89.31 \%$ of the participants. $9.42 \%$ of the participants exhibited symptoms and real-time PCR positive results and Ct values for 3 to 5 weeks (approximately 22 to 35 days). This demonstrated that during the second wave the phenomenon of delayed Ct value between 22 to 35 days increased by three times as compared to the first peak wave of COVID-19. Significantly Delayed Ct positive values were observed among $1.026 \%$ of participants for approximately 5 to 9 weeks (36 to 63 days), indicating that the phenomenon of delayed Ct values for more than 5 weeks (> 36 days) increased by 3.95 times during second COVID-19 wave as shown in Fig. 1.

Of note, among COVID-19 patients during first wave, majority of patients empirically consumed hydroxychloroquine and ciprofloxacin. While during the second wave majority of the patients consumed corticosteroid medications (Table-1). It can be speculated that possibly corticosteroid dexamethasone consumption caused delay of Ct value during second wave of COVID-19.

\section{Discussion}

RNA viruses are rampantly mutating and proliferating and it is speculated that soon these viruses might emerge as highly dangerous entities in the world (12-14). Identification of disease progression patterns is necessary to reduce global burden of disease. It has been reported that viral load and progression to severe disease are correlated (15). Also, the mortality among the Patients with and without cancer can be predicted through the viral load among patients hospitalized with COVID-19 (16).

Among hospitalized patients several studies reported association between Ct value and severity of disease (17-22). Among COVID-19 patients Lower Ct values were correlated with higher lactate dehydrogenase levels, neutrophil counts and high-sensitivity troponin-1 levels; and with lower lymphocyte, T-cell counts, and serum albumin levels (17, 23-25).

Clinical knowledge of SARS-CoV-2 and COVID-19 disease progression is expanding at higher rates. However clinical implications associated with severe aliments or prognoses such as mortality are needed to be further explored. The multivariate logistic regression analyses from viral titers of real-time PCR SARS-CoV-2 positive patient samples revealed that for single unit increase of Ct value, the infectivity (defines as growth in cell culture) decreased by $32 \%$. In other words, lower Ct values were linked with increased probability of viral culture (26). 
A study conducted in 12 patients showed negative correlation of Ct value with C-reactive protein levels (19). Among several patients lower Ct values were significantly correlated with higher levels of creatinine kinase myocardial band (24). The SARS-CoV-2 epidemics analysis in Pakistan revealed delayed cycle threshold (Ct) values in patients infected during second wave of SARS-CoV-2 infections during November and December 2020.

The prevalence rate of COVID-19 during first wave of COVID-19 in Pakistan was 2.17\% higher than the second wave hit during November and December (Data from current study). However, intriguingly, frequent delayed cycle threshold values were observed among COVID-19 patients infected during second wave of SARS-CoV-2 attack. During the second wave of COVID-19, SARS-CoV-2 variants were not prevalent in Pakistan. We asked that among both COVID-19 waves of attack why Ct values varied significantly?

Although people carefully practiced standardized SOPs for prevention against SARS-CoV-2, yet mode of treatment among COVID-19 patients was relatively different. Majority of the people consumed steroids for treatment during second wave of COVID-19. Furthermore, it was observed that usage of corticosteroids significantly delayed Ct values among participants. It can be inferred that frequent usage of corticosteroid might enhance SARSCoV-2 replication. The preliminary findings of current study can further be confirmed through investigating distinct intracellular molecular signaling and in-depth biochemical pathways affecting SARS-CoV-2 replication.

\section{Conclusion}

In conclusion, our study demonstrated that during second wave of COVID-19, the delayed SARS-CoV-2 clearance was associated with early use of corticosteroids. Current study is important for medical research councils at national and international forums and provides useful information for government strategic organizations for re-considering effective therapeutic options against COVID-19.

\section{Abbreviations}

SARS-CoV-2: Severe Acute Respiratory Syndrome Coronavirus 2

WHO: World Health Organization

NCOC: National Command Operation Center

AT2: Alveolar type 2 progenitor

ACE2: Angiotensin-Converting Enzyme 2

XDR: Extensively Drug Resistant

PCR: Polymerase Chain Reaction

Ct: Cycle Threshold

\section{Declarations}

\section{Ethics approval and consent to participate:}

The study has been approved by ethical review board of Islamabad Diagnostic Center Pakistan, and informed patients concern was obtained.

\section{Consent to publication:}

All authors approved the submission of the manuscript for publication

\section{Availability of data and material:}

The data is available and can be used for the academic or research purposes.

\section{Competing interests:}

The authors have no conflict of interest.

\section{Funding:}

No funding was allotted for this study

\section{Authors Contribution:}


$\mathrm{RU}$ is principal investigator (PI) of the study. RU and US conceived the study, US wrote manuscript, analyzed the data and Co-PI of the study; ZZP and SRU performed the experiments.

\section{Acknowledgements:}

We acknowledge the kind efforts of Maj (R) Dr. Aftab Ahmad Khan for discussions and improvement of the study.

\section{References}

1. COVID-19 coronavirus pandemic. May 03, 2021. Online Available via [https://www.worldometers.info/coronavirus/? utm_campaign=homeAdvegas1?]

2. Zou L, Ruan F, Huang M, Liang L, Huang H, Hong Z, et al. SARS-CoV-2 viral load in upper respiratory specimens of infected patients. N Engl J Med. 2020;382(12):1177-9.

3. Hui KPY, Cheung MC, Perera RAPM, Ng KC, Bui CHT, Ho JCW, et al. Tropism, replication competence, and innate immune responses of the coronavirus SARS-CoV-2 in human respiratory tract and conjunctiva: an analysis in ex-vivo and in-vitro cultures. Lancet Respir Med. 2020;8(7):687-95.

4. Puelles VG, Lütgehetmann M, Lindenmeyer MT, Sperhake JP, Wong MN, Allweiss L, et al. Multiorgan and renal tropism of SARS-CoV-2. N Engl J Med. 2020;383(6):590-2.

5. Drosten C, Günther S, Preiser W, van der Werf S, Brodt HR, Becker S, et al. Identification of a novel coronavirus in patients with severe acute respiratory syndrome. N Engl J Med. 2003;348(20):1967-76.

6. Singh Y, Gupta G, Satija S, Pabreja K, Chellappan DK, Dua K. COVID-19 transmission through host cell directed network of GPCR. Drug Dev Res. 2020;81(6):647-9.Return to ref 15 in article.

7. The International News $28^{\text {th }}$ April 2020. 2.229m people to die in Pakistan if lockdown not imposed? Available online [https://www.thenews.com.pk/print/672563-2-229m-people-to-die-in-pakistan-if-lockdown-not-imposed].

8. Saeed U., Uppal SR, Piracha ZZ, Uppal R. Azithromycin Treatment for SARS-CoV-2-related COVID-19 Pandemic Could Worsen Extensively Drug Resistant (XDR) Typhoid: A Risk of Losing the Last Bullet Against Salmonella enterica Serovar Typhi. Jundishapur J Microbiol. Online ahead of Print ; 14(1):e113874. doi: 10.5812/jjm.113874.

9. Dequin, P. F. et al. Effect of hydrocortisone on 21-day mortality or respiratory support among critically ill patients with COVID-19: a randomized clinical trial. JAMA 324, 1-9 (2020).

10. Spagnuolo V, Guffanti M, Galli L, Poli A, Querini PR, Ripa M, Clementi M, Scarpellini P, Lazzarin A, Tresoldi M, Dagna L, Zangrillo A, Ciceri F, Castagna A; COVID-BioB study group. Viral clearance after early corticosteroid treatment in patients with moderate or severe covid-19. Sci Rep. 2020 Dec 4;10(1):21291. doi: 10.1038/s41598-020-78039-1. PMID: 33277573; PMCID: PMC7718220.

11. The Writing Committee for the REMAP-CAP Investigators. Effect of hydrocortisone on mortality and organ support in patients with severe COVID19: the REMAP-CAP COVID-19 Corticosteroid Domain randomized clinical trial. JAMA 324, 1317-1329 (2020).

12. Saeed U, Uppal SR, Piracha ZZ, Rasheed A, Aftab Z, Zaheer H, Uppal R. Evaluation of SARS-CoV-2 antigen-based rapid diagnostic kits in Pakistan: formulation of COVID-19 national testing strategy. Virol J. 2021 Feb 13;18(1):34. doi: 10.1186/s12985-021-01505-3. PMID: 33581714; PMCID: PMC7881305.

13. Saeed U, Uppal SR, Piracha ZZ, Khan AA, Rasheed A, Zaheer H, Aftab Z, Uppal R. Effectivity Analysis of SARS-CoV-2 Nasopharyngeal Swab Rapid Testing Kits in Pakistan: A Scenario of Inadequate COVID-19 Diagnosis. Preprint from Research Square. DOI: 10.21203/rs.3.rs-315851/v1

14. Saeed U, Uppal SR, Piracha ZZ, Uppal R. COVID-19 Transmission via Fomites at Low Temperature: A Potential Silent SARS-CoV-2 Propagation Route. Am J Biomed Sci \& Res. 2021 - 12(1). AJBSR.MS.ID.001716.

15. Sonia N. Rao, Davide Manissero, Victoria R. Steele, and Josep Parejacorresponding author. A Narrative Systematic Review of the Clinical Utility of Cycle Threshold Values in the Context of COVID-19. Infect Dis Ther. 2020 Sep; 9(3): 573-586.

16. Westblade LF, Brar G, Pinheiro LC, Paidoussis D, Rajan M, Martin P, Goyal P, Sepulveda JL, Zhang L, George G, Liu D, Whittier S, Plate M, Small CB, Rand JH, Cushing MM, Walsh TJ, Cooke J, Safford MM, Loda M, Satlin MJ. SARS-CoV-2 Viral Load Predicts Mortality in Patients with and without Cancer Who Are Hospitalized with COVID-19. Cancer Cell. 2020 Nov 9;38(5):661-671.e2. doi: 10.1016/j.ccell.2020.09.007. Epub 2020 Sep 15. PMID: 32997958; PMCID: PMC7492074.

17. Liu Y, Yan LM, Wan L, et al. Viral dynamics in mild and severe cases of COVID-19. Lancet Infect Dis. 2020;20:656-657. doi: 10.1016/S14733099(20)30232-2.

18. Liu YL, Liao W, Wan L, Xiang T, Zhang W. Correlation between relative nasopharyngeal virus RNA load and lymphocyte count disease severity in patients with COVID-19. Viral Immunol. 2020 doi: 10.1089/vim.2020.0062.

19. Liu YY, Yang Y, Zhang C, et al. Clinical and biochemical indexes from 2019-nCoV infected patients linked to viral loads and lung injury. Sci China Life Sci. 2020;63:364-374. doi: 10.1007/s11427-020-1643-8. 
20. Yu XS, Sun S, Shi Y, Wang H, Zhao R, Sheng J. SARS-CoV-2 viral load in sputum correlates with risk of COVID-19 progression. Crit Care. 2020;24:170. doi: 10.1186/s13054-020-02893-8.

21. Zheng SF, Fan J, Yu F, et al. Viral load dynamics and disease severity in patients infected with SARS-CoV-2 in Zhejiang province, China, JanuaryMarch 2020: retrospective cohort study. BMJ. 2020;369:m1443. doi: 10.1136/bmj.m1443.

22. Schwierzeck VK, König JC, Kühn J, et al. First reported nosocomial outbreak of severe acute respiratory syndrome coronavirus 2 (SARS-CoV-2) in a pediatric dialysis unit. Clin Infect Dis. 2020;ciaa491.

23. Huang JTR, Ran RX, Lv ZH, et al. Chronological changes of viral shedding in adult inpatients with COVID-19 in Wuhan, China. Clin Infect Dis. 2020;ciaa631.

24. Yuan CZ, Zhu H, Yang Y, et al. Viral loads in throat and anal swabs in children infected with SARS-CoV-2. Emergin Microbe Infect. $2020 ; 9: 1-17$. doi: 10.1080/22221751.2020.1812436.

25. Azzi LC, Carcano G, Gianfagna F, et al. Saliva is a reliable tool to detect SARS-CoV-2. J Infect. 2020. 10.1016/j.jinf.2020.04.005

26. Bullard J, Dust K, Funk D, et al. Predicting infectious SARS-CoV-2 from diagnostic samples. LID -353 10.1093/cid/ciaa638 [doi] LID - ciaa638. (1537-6591 (Electronic)).

\section{Tables}

Table I. SARS-CoV-2 positive patients and clinical assessment during first two waves of COVID-19 in Pakistan

\begin{tabular}{|c|c|c|c|c|c|c|c|c|c|c|}
\hline $\begin{array}{l}\text { COVID-19 } \\
\text { waves }\end{array}$ & Samples & $\begin{array}{l}\text { Ct } \\
\text { value }\end{array}$ & $\begin{array}{l}\text { RT- } \\
\text { PCR }\end{array}$ & Hydroxychloroquine & Ciprofloxacin & Azithromycin & $\begin{array}{l}\text { Corticosteroid } \\
\text { Treatment }\end{array}$ & Dyspnea & Fever & Cough \\
\hline \multirow{3}{*}{$\begin{array}{l}\text { First wave } \\
\text { (June-July) }\end{array}$} & $\begin{array}{l}\text { Male } \\
(66.92 \%)\end{array}$ & $\begin{array}{l}(15- \\
39)\end{array}$ & + & + & + & - & - & + & + & + \\
\hline & $\begin{array}{l}\text { Female } \\
(33.07 \%)\end{array}$ & $\begin{array}{l}(11- \\
37)\end{array}$ & + & + & + & - & - & + & + & + \\
\hline & $\begin{array}{l}\text { Children } \\
(4 \%)\end{array}$ & $\begin{array}{l}(25- \\
38)\end{array}$ & + & + & + & - & - & - & + & + \\
\hline \multirow{3}{*}{$\begin{array}{l}\text { Second } \\
\text { wave } \\
\text { (November- } \\
\text { December) }\end{array}$} & $\begin{array}{l}\text { Male } \\
(65.7 \%)\end{array}$ & $\begin{array}{l}(12- \\
38)\end{array}$ & + & - & - & + & + & + & + & + \\
\hline & $\begin{array}{l}\text { Female } \\
(34.32 \%)\end{array}$ & $\begin{array}{l}(11- \\
39)\end{array}$ & + & - & - & + & + & + & + & + \\
\hline & $\begin{array}{l}\text { Children } \\
(12.7 \%)\end{array}$ & $\begin{array}{l}(15- \\
35)\end{array}$ & + & - & - & + & + & - & + & + \\
\hline
\end{tabular}

\section{Figures}

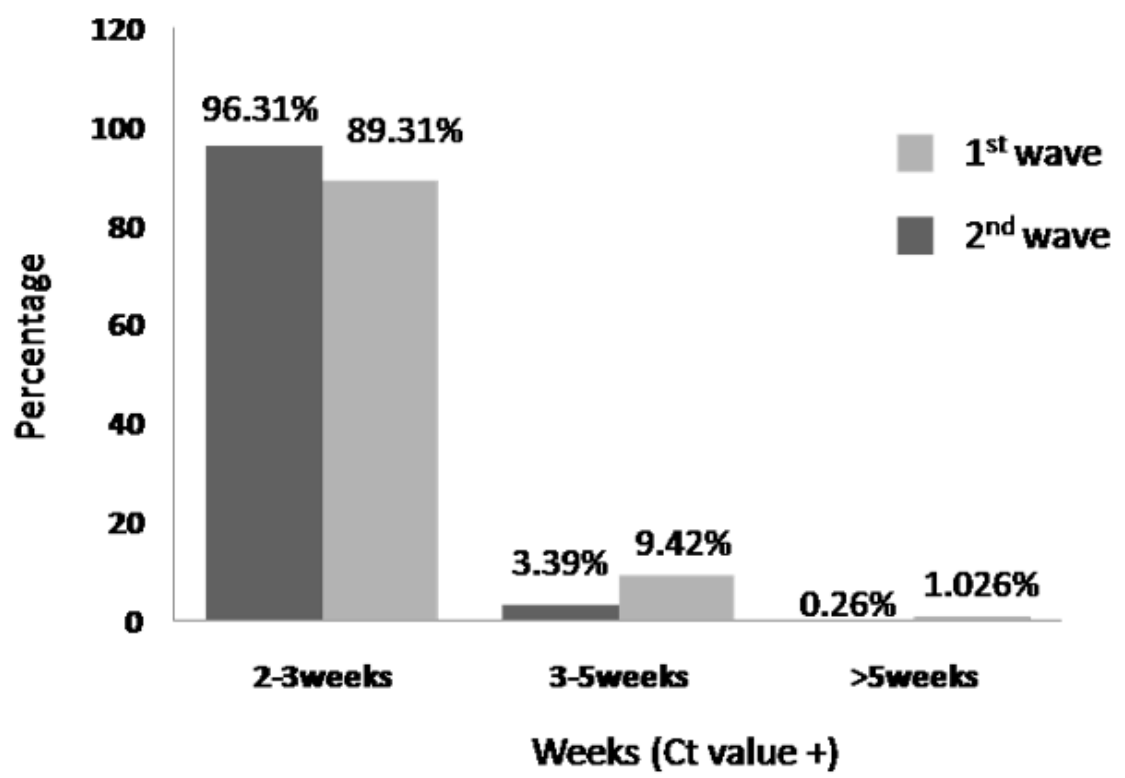


Figure 1

Comparison of Ct value positivity with respect to time among patients infected during first and second waves of COVID-19. 